\title{
O ESTADO BRINCANTE
}

\section{THE PLAYFUL STATE \\ EL ESTADO JUGUETÓN}

Miguel Almir Lima de ARAUJO

\author{
É no domínio dos jogos sagrados que a criança, o poeta \\ e o selvagem encontram um elemento comum. \\ JOHAN HUIZINGA \\ E é o riso que se encarrega de manter essa tensão dialógica \\ em que a consciência se abre, se desprende \\ e se coloca continuamente para além de si mesma. \\ JORGE LARROSA \\ É preciso transver o mundo. \\ MANOEL DE BARROS
}

RESUMO: 0 texto plasma ponderações/meditações acerca do estado brincante desde um horizonte compreensivo que prima por olhares polilógicos e transdisciplinares. Nessa perspectiva, trata do estado brincante como estado de dis-posição e de abertura do senso de humor que viceja a coexistência seminal e in-tensiva entre o corpo e o espírito humanos; como expressão do estado de espanto e de admiração que envolve a inteireza de nosso ser na fruição do impulso lúdico mediante as sensações e sentimentos de bem estar e altivez, de despojamento e gratuidade, de alegria e contenteza; como tradução da plasticidade e do dinamismo rítmico dos fluxos moventes da tragicomicidade do existir que insuflam processos criantes e libertários que implicam na transgressão da sisudez das fôrmas instituídas e compressivas e no envidar de processos de mutação e de emancipação; como o constelar da poeticidade do jogo que perfaz as proezas do cotidiano na expressão do riso e da vivacidade que dão cromaticidade e alumbramento ao existir.

Palavras chave: brincante; impulso lúdico; plasticidade; inteireza; libertário.

RESUMEN: El texto plasma ponderaciones/meditaciones acerca del estado juguetón desde un horizonte comprensivo que prima por miradas polilógicas y transdisciplinares. En esa perspectiva, trata del estado juguetón como estado de dis-posición y de apertura del sentido del humor que nutre la coexistencia seminal e in-tensiva entre el cuerpo y el espíritu humanos; como expresión del estado de espanto y de admiración que envuelve el entero de nuestro ser en la fruición del impulso lúdico mediante las sensaciones y sentimientos de bienestar y altivez, de despojamiento y gratuidad, de alegría y contento; como traducción de la plasticidad y del dinamismo rítmico de los flujos móviles de la tragicomedia del existir que insuflan processos creantes y libertarios que implican en la transgresión de la rigidez de los moldes instituidos y compresivos y en el engendrar de procesos de mutación y de emancipación; como el constelar de la poeticidad del juego que perfina las proezas de lo cotidiano en la expresión de la risa y de la vivacidad que dan cromaticidad y alumbramiento del existir.

Palabras clave: Juguetón; Impulso lúdico; Plasticidad; El entero; Libertario.

ABSTRACT: The text makes considerations/meditations about the playful state from a comprehensive horizon that highlights polylogical and transdisciplinary looks. In this perspective, it treats the playful state as a state of dis-position and openness of the sense of humor that favors the seminal and in-tensive coexistence between the human body and the spirit. This being an expression of the state of astonishment and admiration which surrounds the wholeness of our being in the enjoyment of the playful impulse through sensations and feelings of well-being and pride, of detachment and gratuity, of joy and contentment. In addition, as a translation of the plasticity and rhythmic dynamism of the moving flows of existence tragicomicity that instill creative and libertarian processes that imply both in the transgression of the austerity of the instituted and compressive forms and in the processes of mutation and emancipation. And also, as a constellation of the poeticity of the game that performs the prowess of daily life in the expression of laughter and vivacity that provide chromaticity and enlightenment to exist.

Keywords: playful; playful impulse; plasticity; wholeness; libertarian.

\footnotetext{
${ }^{1}$ Professor Pleno da Universidade Estadual de Feira de Santana-UEFS. Doutor em Educação. E-mail: malmir2@gmail.com
} 
O estado brincante é o estado de abertura da alma e do corpo - como constitutivos estruturantes e visceralmente coexistentes - em que nos dis-pomos, com despojamento, a viver as intensidades das proezas e contingências de cada momento, as dobras e curvas das aventuras cotidianas, as pulsões das proezas e travessuras que nos movem e envolvem na fruição de sensações e de sentimentos de bem estar e vivacidade, de alegria e contenteza. É o estado em que nos desprendemos das armaduras que nos impõem através da cultura do siso, da sisudez, instituída pelos conservadorismos e moralismos compressivos; em que nos movimentamos e nos libertamos das pesuras dos fardos que asfixiam e, assim, fazemos irromper a gratuidade, a leveza e a graça do riso que faz jorrar o impulso vital que exulta corpo e alma; que nos areja e vivifica, anima e renova por inteiro.

O estado brincante revela-se mediante a presença seminal dos estados de humor - de húmus que conota vigor - que se projetam no espírito de dis-posição e de desnudamento, na presença do riso maroto e irradiante que contamina com emoções e sentimentos de alegria e de tranquilidade, de graça e de ternura. Huizinga (1971, p. 13) proclama que "O jogo lança sobre nós um feitiço: é 'fascinante', 'cativante'. Está cheio das duas qualidades mais nobres que somos capazes de ver nas coisas: o ritmo e a harmonia". Os influxos e proezas das atividades lúdicas, com seus jogos sincopados, envolvem o ser humano por inteiro incidindo em momentos de fruição penetrante e prazenteira que envolvem, cativam e fascinam. Luckesi (1998, p. 27) realça que as atividades lúdicas trazem a "plenitude da experiência". E desdobra: "A atividade lúdica é aquela que dá plenitude e, por isso, prazer ao ser humano, seja como exercício, seja como jogo simbólico, seja como jogo de regras. Os jogos apresentam múltiplas possibilidades de interação consigo mesmo e com os outros" (LUCKESI, 1998, p. 29).

A dimensão poética do estado brincante mobiliza nossos imaginários, nosso inconsciente coletivo atravessando o campo simbólico de nossos existires em que se plasmam o jogo das imagens que sedimentamos nas vivências cotidianas. Esse campo do imaginário, com a plasticidade de seu dinamismo, nos impulsiona às proezas das aventuras que expressam as intensidades de nossos sensos intuitivos e afetivos que nos comovem por inteiro; fomenta nossa imaginação criante, nosso senso de espirituosidade para a percepção das sutilezas e finezas do existir; aguça o estado onírico em que projetamos nossas fantasias, delírios e devaneios.

As experiências lúdicas, com seus tons encurvados, ao mobilizar, de modo implicado, corpo e espírito, nos dis-põem e envolvem integralmente no suceder rítmico das intensidades de momentos comoventes e benfazejos. Momentos que fazem jorrar os fluxos de sensações e sentimentos vivificantes, extraordinários. O estado brincante implica na expressão livre e despojada de nossa corporeidade, das intensidades dos movimentos das pulsões do corpo penetrando nos desvãos de sua complexidade e de suas ambiguidades.

Nas texturas de nosso cotidiano, de modo geral, somos condicionados por padrões modelares (fôrmas) de comportamentos que tendem a comprimir as expressões originárias de nossas emoções, energias e sentimentos. Somos aprisionados pelos ditames de regras e normas que impõem, disciplinarmente, atitudes normalizadas (normóticas) que recalcam a 
espontaneidade, as manifestações singulares de cada subjetividade. Somos enclausurados em fôrmas que nos deformam, que reprimem as expressões viscerais de nosso existir. Esse processo de regulação pretende nos confinar em currais como se fôssemos rebanhos que devem ser controlados e domesticados. Desse modo, até o brincar, o estado brincante tende a ser disciplinado e normatizado pelos poderes instituídos (escolas, famílias, igrejas...). A espontaneidade, as expressões mais internas e orgânicas são comprimidas por essas normas externas que impõem comportamentos uniformizados e conformadores.

As manifestações lúdicas descortinadas através das brincadeiras, dos jogos, das cantigas, danças, entre tantas outras expressões e que proporcionam o estado brincante, se configuram como tradução visceral da liberdade, do estado de graça - do gracioso -, da autenticidade; como diluição da rigidez que atrofia, amedronta e controla. Obviamente que isso não é interessante para os protagonistas dos poderes instituídos com seus processos disciplinares e cerceadores. Estes carecem de pessoas bem comportadas e domesticadas pelas lógicas enrijecidas e austeras que incidem em conformismo e subordinação. O estado brincante desinstala; é essencialmente libertário, emancipador. Revela a afirmação dos desejos e sonhos de cada subjetividade; da rebeldia de espíritos livres que criam e recriam (recrear) seu existir no mundo. o próprio vocábulo recreação já supõe processos de recriação, de reinvenção, de expressão livre de emoções, sentimentos e valores.

De modo geral, não nos damos conta de que a palavra recreação significa recriação, expressão livre dos sentires, dos desejos, da imaginação que leva a processos constantes de reinvenção da vida, aos desvãos dos sonhos e utopias que nos impulsionam. Não é à toa que até os momentos de recreio nas escolas tendem a ser tutorados, controlados por funcionários e professores (pro-feitores?) das prisões escolares - salvo as exceções de escolas que não se confinam a meras prisões. Liberdade incomoda, desinstala, pois afirma a vida, as expressões livres e as pulsões moventes do viver. Pessoas altaneiras, que cultivam as liberdades humanas, rompem com as prisões institucionais e fazem a vida, o espírito irreverente e transgressivo eclodir com sua força desinstaladora, renovadora e transformadora.

No filme "O nome da rosa", temos um exemplo ilustrativo da ameaça que o riso, como uma metáfora que traduz o estado brincante, apresenta para os poderes monológicos e sisudos. O livro "A poética", de Aristóteles, é proibido de ser lido no mosteiro apenas pelo fato de que nele o autor trata do riso. Diante do poder austero das autoridades do mosteiro, o livro "A poética" representava uma ameaça, um risco, sendo, portanto, considerado diabólico, pecaminoso e, portanto, abominável. o perigo era tal que o livro foi envenenado de modo que todos os que nele tocassem seriam mortos. As expressões da liberdade que o riso traz são, de modo predominante, malquistas e recalcadas pelos poderes instituídos com seus modelos uniformizados/uniformizantes e repressores. $O$ riso é perigoso e desconcertante; opera a relação dialógica que entrecruza o profano e o sagrado, o imanente e o transcendente, o trágico e o cômico; dissolve as dicotomias que separam e isolam os diversos e os interliga. Ao sacudir os formatos do instituído o riso instala o espírito de dúvida, o germe da suspeição, a ironia desconcertante que perfura e desmonta os artifícios ostensivos da razão cínica. Riso rima com risco, com torsão e desestabilização. 
Obviamente que o riso, como expressão do humano, da cultura humana, apresenta conotações diversificadas no bojo de sua polissemia incluindo dimensões pejorativas como o riso sarcástico, mesquinho e insano. Realçamos neste texto as conotações de riso que afirmam e dão gosto ao humano, que potencializam vivências qualitativamente libertárias, transformadoras e afirmadoras do existir altaneiro.

O riso se apresenta de modo incontornável. Escapa os contornos das formas-fôrmas com suas características fixas e duras; instala-se e projeta-se diante do inusitado, do inesperado e do surpreendente, de situações absurdas do cotidiano (BERGSON, 2007). Em suas meditações acerca do riso Bergson (2007, p. 148) realça que este "Como espuma, fervilha. É alegria". O riso é a expressão borbulhante da alegria que traz graça e contenteza. "Há no riso sobretudo um movimento de relaxamento" (BERGSON, 2007, p. 144. Grifo do autor). O riso também potencializa esse estado de relaxamento que traz leveza ao corpo e à alma.

Larrosa (1999, p. 181) afirma que "O riso destrói as certezas. E especialmente aquela certeza que constitui a consciência enclausurada: a certeza de si. [...] 0 riso permite que o espírito alce voo sobre si mesmo. O chapéu de guizos tem asas". O riso, com seus chapéus de guizos, provoca balanceios e ruídos que racham as certezas fixas e imóveis, desmancha os disfarces do cinismo. "O riso questiona os hábitos e os lugares comuns da linguagem. E, no limite, o riso transporta a suspeita de que toda linguagem direta é falsa, de que toda vestimenta, inclusive toda a pele, é máscara" (LARROSA, 1999, p. 178). Rasga as cascas dos artefatos da linguagem rotineira e mecanizada do cotidiano, dos constructos dos discursos formatados linearmente e penetra no âmago destes desvestindo as máscaras que velam os fenômenos, a vida; nos aproxima dos começos, dos estados originários em que a vida pulsa em seus fluxos livres. Como poetiza Barros (2004, p. 47) "Eu queria avançar para o começo. Chegar ao criançamento das palavras". Criançamento em que as palavras podem lavrar as intensidades e a vivacidade dos sentidos existenciais, alumbrantes.

O riso é uma das características primordiais do estado brincante ao proporcionar a este plasticidade, abertura e graça. O estado brincante é portador de uma significativa dimensão estética ao mobilizar nossa sensibilidade para o admirante, ou seja, para a fruição de sensações que trazem o sabor do gosto que agrada e apraz; ao potencializar experiências sensíveis que mobilizam o estado poético como expressão do espanto, da experimentação de sensações inusitadas, da criação de sentidos novos, da fruição da liberdade; ao nos adentrar na desmesura e na plasticidade de aventuras extraordinárias.

Schiller (1989, p. 73) declara que "O objeto do impulso lúdico, representado num esquema geral, poderá ser chamado de forma viva, um conceito que serve para designar todas as qualidades estéticas dos fenômenos, tudo o que em resumo entendemos no sentido mais próprio por beleza". Ao potencializar a expressão das formas vivas o impulso lúdico nos precipita na plasticidade dos fenômenos proporcionando, assim, a fruição da beleza mediante a postura admirante que nutrimos em relação a estes.

O espírito brincante é saboroso e movente, transgressivo e metamorfósico; desinstala a rigidez da ordem estabelecida; instala a desordem que sacode e altera a ordem obsoleta; cria a dança complementar e movente entre ordem e desordem, entre cosmos e caos dando ritmo, 
intensidade e movimento às travessias humanas. Huizinga (1971, p. 12), referindo-se aos fluxos do jogo, assevera: "Enquanto está ocorrendo tudo é movimento, mudança, alternância, sucessão, associação, separação". No movimento da gangorra do estado brincante vivenciamos o balancê que impulsiona o impulso vital das andanças cotidianas em seus compassos recurvados.

O estado brincante desconstrói as máscaras e estruturas da normalidade das coisas que normaliza (normotiza) e domestica as pessoas mediante os padrões previsíveis de comportamentos cristalizados e unidimensionalizantes e faz despontar a loucura do espírito inventivo e transformador. O estado brincante é subversivo ao transgredir as fôrmas da ordem enrijecida que cerceiam a expressão livre de cada subjetividade. Somente os que são acometidos com o germe da loucura criante ousam transgredir as fôrmas emboloradas da rotina e da normalidade cinzenta; experimentam os processos de transformação, as metamorfoses que tornam a vida sempre rediviva.

As urdiduras do estado brincante se manifestam através dos jogos sincopados em que o corpo e a alma dançam, recreiam/recriam e celebram as intensidades do viver na cadência rítmica de cada momento. Assim, nos movimentos dos jogos, das proezas lúdicas, a linearidade e a rigidez das atitudes e comportamentos padronizados e solidificados são desconstruídos e os corpos se recriam, se inventam e reinventam outros modos de traçar, compor e dançar sua destinação no mundo. Os movimentos livres e criantes dos exercícios lúdicos jogam o mundo de ponta cabeça como nos compassos recurvados da capoeira, das cambalhotas, dos saltos "mortais" para que o experimentemos de novos modos, com novos tons e com mais plasticidade e vigor.

Assim, nas travessuras das experiências lúdicas corpo e alma se desamarram das correntes que os aprisionam e podem celebrar a condição de estarem livres, de expressar os delírios da imaginação, da fantasia, que potencializam o desbordar de novas formas de ser e de estar no mundo; adentram-nos no estado de distração, de vadiança em que sentimos o gosto e o gozo da alegria desmesurada. Essas novas formas implicam em deslocamentos que nos fazem exercitar os desapegos, os despojamentos, as descobertas que alargam e que trazem leveza e abertura, contenteza e vivacidade, pulsão e encantamento. o lúdico se plasma na expressão da gratuidade, do desnudamento, da fruição de sentimentos fundos e originários que emergem dos desvãos da alma e que vibram nas pulsões do corpo - na coexistência visceral entre ambos.

No mundo em que vivemos predominam as lógicas funcionais e utilitárias que impõem os formatos e posturas em que quase tudo se converte em negócio. Nessa esfera, tem relevância aquilo que tem valor utilitário, operacional e funcional que pode ser comprado e vendido, que implica em benefícios mercantis. Essa perspectiva se traduz no predomínio do ter em detrimento do ser, da quantidade sobre a qualidade, do funcional sobre o humano. Assim, o ócio, as atitudes e ações que revelam gratuidade e despojamento tendem a ser denegadas, desqualificadas e excluídas. Não se cabem nas fôrmas utilitárias que reduzem o humano a objeto mercantil. A graça das estampas do lúdico é desfigurada com a "des-graça" sombria da supremacia das posturas meramente utilitárias e funcionais.

$\mathrm{Na}$ própria etimologia da palavra negócio encontramos essa tradução da negação do lúdico, do ócio: neg-ócio. No bojo dessas lógicas, negócios são feitos com posturas “sérias”, mecânicas 
e funcionais, imbuídas de sisudez e frieza. o ócio é a expressão da liberdade do ser, da gratuidade, dos recônditos internos e incontornáveis do humano, e isso não interessa aos negócios dos imperativos do ter que privilegiam a ordem do externo, a lógica do custo-benefício. O riso do ócio, do estado brincante desconstrói a pesura do siso, dos determinismos supostamente implacáveis que bloqueiam a expressão do indeterminado, do contingente, do orgânico com suas potências inaugurais, renovadoras. As posturas austeras do siso propagam uma atmosfera esmaecida e asfixiante, marcada por certa morbidez.

Nos processos que instauram as lógicas do consumismo, sobretudo na contemporaneidade mais recente, o filão do lúdico, do jogo, tem sido, em grandes proporções, utilizado como armadilha para seduzir e anestesiar as pessoas nas malhas desse consumismo. Através dos mais diversos dispositivos do marketing as grandes corporações mercantis, as mídias, investem pesado no uso dos dispositivos lúdicos como estratégias perspicazes para fomentar a histeria do consumismo que tanto consome e domestica as pessoas (propagandas, novelas, shows business...). Como tudo que é humano, as experiências lúdicas também são passíveis de serem instrumentalizadas e utilizadas para fins meramente utilitários e até insanos. Esse fato revela que, mesmo diante de expressões que caracterizam as dimensões mais despojadas e livres do existir, precisamos exercitar constantemente nosso senso de criticidade e de espirituosidade para não sermos ludibriados.

Em seus sentidos primordiais, o estado brincante é ridente. Neste, o riso largo, desmedido e penetrante desobstrui a rigidez que se instala na alma e no corpo fazendo eclodir a intensidade dos sentimentos espontâneos e viscerais que perfazem cada subjetividade. Assim, corpo e alma - cada subjetividade - voam com os pés fincados na terra em estado de pipas ao vento; se lançam no descortinar de novos horizontes que levam às buscas do extraordinário como instância que ultrapassa a rotina linear do ordinário esmaecido. A pesura e a rigidez das fôrmas do ordinário nos impedem de abrirmos as asas para alçar nossos próprios voos; as mantém aprisionadas e rastejantes nos poleiros instituídos, tanto de forma visível, como invisível (cabrestos invisíveis).

Enquanto o siso é monológico, o riso é dialógico. O siso impõe normas e posturas uniformes e cerceadoras enquanto o riso as desconstrói primando pela pluralidade, pela diversidade. O siso se fecha e se enrijece em sua austeridade para controlar e reprimir tendendo a posturas rancorosas e ressentidas. $O$ riso abre e flexibiliza para descomprimir e libertar primando por posturas de simpatia e generosidade. $\mathrm{O}$ siso é sólido e hostil; distancia e exclui. O riso é líquido e cordial; aproxima e inclui. $O$ siso é fixo/fixista e linear. $O$ riso é movente, ondulante. $O$ siso, de modo predominante, dissimula e disfarça nas astúcias e armaduras de suas máscaras. 0 riso não carece de artifícios dissimuladores, se projeta de modo leve, transparente e desarmado.

Há uma frase lapidar muito presente no imaginário popular que afirma: brincadeira é coisa séria. As experiências lúdicas são imensamente sérias ao revelarem, de forma desnuda, os impulsos e as sensações que emergem de dentro de cada um de nós, da cepa dos sentimentos. O estado lúdico/brincante é essencialmente orginário e verdadeiro. Traduz despojamento de corpo e alma; um estado expressivo de concentração e de relaxamento em que a consciência está 
centrada em si mesma e em que estamos enraizados em nossa internidade. O lúcido e o lúdico são dimensões visceralmente interligadas e complementares. A interligação dessas instâncias conduz a percepções e fruições vigorosas do pensar e do sentir, do existir e do co-existir cotidiano.

As intensidades das vivências com a ludicidade nos conduzem a processos que mobilizam com profundidade as dimensões internas de cada um de nós e incidem em experiências de autoconhecimento. Esses compassos de autodescoberta, de vivências internas, potencializam ações expressivas de compreensão da consciência de si mesmo, de nossos limites e possibilidades, de afinação dos processos de autopercepção, busca do si próprio, enfim, do autoconhecimento. 0 estado brincante, ao nos desatar dos nós e das máscaras que nos sufocam e escondem nos faz rir de nós mesmos; leva a deslocamentos que nos instigam na ruptura dos grilhões que aprisionam; potencializam os processos de autotransformação.

O estado brincante implica em momentos intensos de comicidade, de expressão desnuda da alegria e da contenteza que animam, vivificam e alumbram o existir; que tornam nossas vidas graciosas; que trazem bem estar interno; que fortalecem a autoestima e a disposição para os desafios do cotidiano. Potencializa a manifestação do pathos, das paixões e dos sonhos que arrepiam, entusiasmam e impulsionam às buscas. As aventuras brincantes nos enredam na ciranda dos encontros em que nos compartilhamos uns com os outros, em que, como vimos, expressamos emoções e sentimentos que vivificam e dão encantamento. Essas ações de compartilhamentos nos dis-põem para momentos de maior interligação na aproximação de uns para com os outros no envidar do altruísmo em que são afirmados e realçados os valores da solidariedade, da amorosidade; a fruição do prazer e da alegria de estar juntos. Bergson (2007, p. 146) ao falar do riso proclama que "Ele não atingiria seu objetivo se não trouxesse a marca da simpatia e da bondade".

Os movimentos transversais do lúdico nos movem, co-movem e nos fazem reinventar as sagas do viver. Seus malabarismos nos arremessam nas ventanias das proezas em que nos movemos e reinventamos por dentro - e por fora. São movimentos que compelem os ventos da fantasia, da imaginação e que nos levam às danças criativas, recreativas, celebrativas; às inventanias que renovam, reinventam e alumbram. Nos adentram na movência dos ritos individuais e coletivos de celebração, de afirmação e de renovação da vida.

O espírito brincante é expressivamente traduzido nas imagens da criança, do palhaço e do bufão como espectros que revelam a postura ridente. Essa postura conota espontaneidade e leveza, desconserta e desconstrói; opera deslocamentos e trans-formações. De modo travesso, espirituoso e sutil a criança, o palhaço e o bufão jogam com as formas-fôrmas, com os padrões e armaduras enrijecidas, com as máscaras que disfarçam e escondem, nos desnudando, nos pondo nus diante de nós mesmos, das contingências do viver cotidiano. Desse modo, as ordens lineares e sisudas são desestabilizadas e ridicularizadas para que enxerguemos os meandros internos das coisas, dos fenômenos e da vida de forma transparente, despojada e autenticamente.

Larrosa (1999, p. 180) pontua que

Os personagens que encarnam o riso possuem uma subjetividade descentrada. São almas sem 
pátria, formas de consciência sempre provisórias, sempre emprestadas, que também sabem encenar sua própria contingência, aniquilar sua própria satisfação e corrigir ironicamente suas falsas pretensões de universalidade.

Destarte, esses personagens se encontram na posição de entre-lugar, apresentam identidades múltiplas e flexíveis, estão em processos permanentes de mutação, e, portanto, rompem com as leis uniformizadas e estáticas das universalidades abstratas e descontextualizadas do ritmo dinâmico do viver cotidiano; borram e perfuram as máscaras e redomas que dão suporte às hipocrisias, às roupagens das mentiras que distorcem a realidade e a apresentam de forma nua, escancarada; percebem, como a criança da fábula de Andersen (2016), que o "rei está nu" apesar de todos, imbuídos dos véus dos condicionamentos e mecanismos disfarçantes, acharem que o rei está paramentado em seus ritos mecânicos e dissimuladores em que a mentira se impõe como verdade.

O estado sapeca e maroto do espírito de criança, com suas posturas de leveza e de gratuidade, de despojamento e de alegria, que se projeta no estado brincante, nos impulsiona aos processos de fruição e de criação/recriação permanentes da dança do existir e do coexistir mediante os fluxos das intensidades de seu vigor seminal, de seus rodopios constantes.

O espírito brincante, portanto, nos lança pelos desvãos da loucura transgressiva que nos leva ao reencontro com nossa criança interna nos fazendo criar a dança que potencializa o inventar nossa própria destinação no mundo. Assim, podemos celebrar as liberdades que nos dignificam, os laços que nos entrelaçam uns com os outros, as estripulias que nos trançam nas rodas das folias, do compartilhamento do ser sendo com os outros.

As aventuras lúdicas do estado brincante implicam em grandes desafios e riscos. Por isso, carece de que tenhamos dis-posição de corpo e de alma para mergulharmos nas ondas tortuosas dessas proezas; de espíritos audaciosos que se projetam, com coragem e abertura, nos riscos que proporcionam desapegos, descobertas, superações e metamorfoses. Os desafios das experiências lúdicas suscitam tensões que, conduzidas de forma criativa e sensível, desembocam em processos de crescimentos, de conquistas e de transformações que afirmam, animam e expandem nossa subjetividade. Huizinga (1971, p. 21) afirma que são "características lúdicas: ordem, tensão, movimento, mudança, solenidade, ritmo, entusiasmo". Ao mobilizar essas múltiplas dimensões as experiências lúdicas nos compelem à fruição da inteireza do existir humano, aos riscos e compassos de aventuras que nos co-movem por inteiro e que nos tornam seres mais abertos, audaciosos e livres.

Larrosa (1999, p. 179) acentua que “[...] essa tensão que torna ambíguo tudo aquilo que toca, essa suspensão instantânea da realidade e de seus valores, esse momento de oscilação entre o ser e o não ser, essa é a brecha que abre o riso e em que o riso se instala como um ácido que a tudo corrói”. Essa potência tensionadora do riso penetra de modo capilar nas ambiguidades dos fenômenos da vida provocando torsões e rasgos que podem instalar alterações e mudanças significativas; podem jorrar lampejos libertários.

Os formatos de alguns jogos lúdicos comumente são imbuídos de regras que aparecem como dispositivos que suscitam desafios às nossas capacidades criativas e inventivas. As regras dos jogos não se traduzem, de modo geral, em imposições cerceadoras e compressivas, mas em instrumentos estimuladores para que os jogantes reinventem e recriem em seus processos de 
jogância. Nas esferas de seus limites as regras dos jogos apresentam possibilidades para que os jogantes as desafiem e ultrapassem com seus feitos inusitados e surpreendentes. As leis do ordinário instituído nas regras dos jogos devem impulsionar os brincantes a incrementar ações extraordinárias, novos modos de fruição lúdica, de expressão do espírito inventivo e transgressivo.

Comumente, como vimos, somos condicionados e até adestrados nos padrões e medos que nos impedem de sermos nós mesmos, que comprimem os sentires originários e que nos escondem e aprisionam em redomas. Cultivar o espírito brincante supõe desafiarmos as amarras desses medos e nos lançarmos nos voos que permitem sermos nós mesmos, que levam à expressão livre dos desejos e paixões mediante os influxos do coexistir. Supõe as iniciações permanentes através das experiências que nos desafiam nos processos de desatamento desses nós que nos amarram e impedem de nos jogarmos pelos desafios do viver, pelos abismos do mundo; de jogarmos o jogo desafiante das proezas do cotidiano. Jodorowski (2009, p. 141) assevera: "A vida se resume ao passatempo que cada um tem para si. Jogue o seu jogo". Nos fluxos sincopados da jogância de nossos jogos, podemos descortinar, de forma prazenteira, altiva e graciosa as dobras das encruzilhadas que perfazem o existir humano.

o espírito brincante se revela mediante as curvas e as frestas do vazio, do estado de esvaziamento que potencializa a expressão do espírito criante, dos voos da liberdade. A plasticidade dos movimentos lúdicos carece de espaços vazios (internos e externos), de horizontes abertos para que possa se manifestar na cadência rítmica de seu espírito fagueiro. Vazio como estado de disposição, de abertura, de despojamento, de relaxamento que potencializa a emergência e a vivência das aventuras lúdicas, das piruetas que perfazem o estado brincante.

Nesse horizonte, o estado brincante é um estado de fruição das intensidades que perfazem o viver, em suas dimensões orgânicas e anímicas, vastas e fundas, no cultivo de emoções e de sentimentos que nos vivificam e fazem renascer nos fluxos recurvados das travessias cotidianas. Barros (2004, p. 75) poetiza: "A expressão reta não sonha". São os fluxos das ondulações das contingências, do jogo indeterminado e fractálico dos fenômenos e das experiências que nos impulsionam aos sonhos, que nos compelem ao viver intensamente.

O estado brincante faz jorrar as estampas de nosso ser-sendo-com mediante as proezas dos riscos e desafios que nos convocam às buscas intensas das liberdades, das paixões e sonhos que infundem vivacidade ao existir/coexistir. O estado brincante nos enreda na poeticidade das intensidades do viver aos nos possibilitar a vivência, a fruição do dinamismo e da plasticidade dos compassos rítmicos das travessias humanas proporcionando-lhes graça e radiância, cromaticidade e encantação; potencializa o desbordar da trama entrelaçada da tragicomicidade da vida que entrecruza o trágico e o cômico, o agreste e o doce - o agridoce - do humano.

O estado brincante se traduz na postura de despojamento em que o corpo e alma dançam nas proezas de cada momento.

Viver o fluxo das intensidades 
das curvas e dobras das aventuras que nos comovem por inteiro no ritmo das travessias/travessuras.

O estado brincante impulsiona a romper o peso das armaduras a nos libertar da rigidez do siso e buscar a leveza e a ternura.

Os poderes instituídos impõem fôrmas sisudas para controlar recalcam o estado brincante para assim cercear e subordinar.

$\mathrm{O}$ riso dissolve as couraças a pesura do siso, da compressão faz irromper a leveza e a graça a espontaneidade e a encantação.

Traz alegria e vivacidade areja e dá ritmo ao vivimento anima e renova nosso existir traz folia e contentamento.

Recreação implica em recriação no dinamismo do jogo sincopado na expressão livre dos sentires no ritmo travesso do rebolado.

O estado brincante é subversivo desinstala a ordem estabelecida que nos sufoca, reprime e conforma plasma a expressão livre da vida.

O siso é monológico e enrijecido o riso é dialógico e dançante o siso é uniforme e retilíneo o riso é pluralista e ondulante.

O jogo do lúdico nos desafia nos fluxos de sua plasticidade joga o mundo de ponta a cabeça nas cambalhotas da liberdade.

Os negócios da ordem do ter nos reduzem a entes utilitários a gratuidade do estado brincante desborda nosso ser libertário.

Nos desvãos do estado brincante descortinamos a vida sem cabimento vivenciando momentos extraordinários em estado elevado de pipas ao vento. 
O jogo do lúdico envolve e arrepia fomenta a fantasia, a imaginação nosso espírito maroto e inventivo nos trazendo magia e celebração.

O estado de leveza e abertura nos dispõe para o arco da simpatia no compartilhamento com os outros cultivando a nobreza da empatia.

Nos desafios do jogo vivente os riscos que nos açoitam fagueiros no perigar que nos move e anima nas ações que nos fazem altaneiros.

O riso desconstrói padrões fixos instala a forma viva, a vibração em que a vida pulsa com seu vigor no gosto do espanto, da admiração

O estado menino de ludicidade nos fascina, é mui prazenteiro traz contenteza e bem estar vivifica nosso ser por inteiro.

O estado brincante se projeta nas proezas e fluxos do movimento que embala os compassos do viver nas curvas de seu destinamento.

Nos conduz para dentro de nós mesmos no cuidado com o autoconhecimento em que rimos de nossas pequenezas e nos buscamos com desprendimento.

A fruição do estado brincante estampa a intensidade dos momentos entrelaça o doce e o amargo da vida trazendo boniteza e alumbramento.

\section{REFERÊNCIAS}

ANDERSEN, H. C . https://pt.wikipedia.org/wiki/A_Roupa_Nova_do_Rei. Acesso em 10/11/2016.

BARROS, M. de. Livro sobre o nada. Rio de Janeiro; São Paulo: Record, 2004.

BENJAMIN, W. Reflexões: a criança, o brinquedo, a educação. São Paulo: Summus, 1984.

BERGSON, H. O riso: ensaio sobre a significação da comicidade. São Paulo: Martins Fontes, 2007. HUIZINGA, J. Homo ludens: o jogo como elemento da cultura. São Paulo: Perspectiva/EDUSP, 1971.

JODOROWSKI, A. A dança da realidade. São Paulo: Devir, 2009.

LARROSA, J. Pedagogia profana: danças, piruetas e mascaradas. Belo Horizonte: Autêntica, 1999.

LUCKESI, C. C. Desenvolvimento dos estados de consciência e ludicidade. Cadernos de Pesquisa. 
Interfaces da Educação. Salvador: UFBA; Programa de Pós-Graduação e Pesquisa/FACED, 1998. MARCELINO, N. C. Pedagogia da animação. Campinas, SP: Papirus, 1990.

PORTO, B. S. (Org.) Ludicidade: o que é mesmo isso? Salvador: UFBA; FACED; PPGE; CEPEL, 2002.

RETONDAR, J. J. M. Teoria do jogo. Petrópolis, RJ: Vozes, 2007.

Revista da FAEEBA: Educação e contemporaneidade. Educação, arte e ludicidade. V. 15, n. 25, p. 157-162, jan./jun. 2006, UNEB, Salvador.

SCHILLER, F. A educação estética do homem. São Paulo: Iluminuras, 1989. 